\title{
O RECONHECIMENTO DOS REFUGIADOS AMBIENTAIS NO ÂMBITO DO SISTEMA INTERAMERICANO DE PROTEÇÃO AOS DIREITOS HUMANOS
}

\author{
Anna Luisa Walter de Santana Daniele \\ Doutoranda em Direito pela Pontifícia Universidade Católica do Paraná, Campus Curitiba - \\ Brasil. Mestre em Direito do Estado pela Pontifícia Universidade Católica de São Paulo - \\ SP. Professora universitária. E-mail: <annaluisasantana@hotmail.com>.
}

\section{Danielle Anne Pamplona}

Doutora em Direito pela UFSC - Universidade Federal de Santa Catarina - Florianópolis. International Visiting Scholarna American University - Washington, DC, EUA (2015-2016). Professora Titular do Programa de Pós-Graduação em Direito da Pontifícia Universidade Católica do Paraná, Campus Curitiba. Coordenadora da Clínica de Direitos Humanos do PPGD/PUC-PR. E-mail: <dapamplona@pamplonaebraz.com.br>.

\begin{abstract}
Resumo: Trata-se de artigo que discute o reconhecimento da categoria dos refugiados ambientais no âmbito do Sistema Interamericano de Proteção aos Direitos Humanos. Refugiados ambientais são todos aqueles que precisam cruzar a fronteira de seu país, abandonando suas residências habituais, em razão de condições ambientais degradantes que impedem uma vida digna e muitas vezes colocam em risco a própria sobrevivência de determinado grupo social. Sustenta-se o reconhecimento dos refugiados ambientais na Declaração de Cartagena, já que refugiados ambientais sofrem graves violações de direito humanos quando a ausência de um meio ambiente equilibrado exige que abandonem suas casas e os forçam a uma migração. Diante desse reconhecimento na Declaração de Cartagena, entendemos que o Sistema Interamericano de Direitos Humanos é o locus adequado para a proteção daqueles que se encontram em situação de refúgio motivado por causas ambientais.
\end{abstract}

Palavras-chave: Refugiados ambientais. Sistema Interamericano de Proteção aos Direitos Humanos. Declaração de Cartagena.

Sumário: 1 Introdução - 2 Meio ambiente equilibrado como direito humano - 3 Deslocados ambientais 4 Refugiados ambientais - $\mathbf{5}$ Conclusões - Referências

\section{Introdução}

O presente artigo propõe a discussão da temática dos refugiados ambientais no âmbito do Sistema Interamericano de Proteção dos Direitos Humanos. A importância da discussão da temática leva em consideração as profundas e degradantes consequências do desequilíbrio ambiental no mundo. 
O Acordo de Paris, ratificado pelo Brasil em setembro de 2016, resultado da Conferência do Clima de Paris (COP 21), inicia seu texto justamente reconhecendo que as mudanças climáticas representam uma ameaça urgente e potencialmente irreversivel para as sociedades humanas e o planeta.

Refugiados ambientais são todos aqueles que precisam cruzar a fronteira de seu país, abandonando suas residências habituais, em razão de condições ambientais degradantes que impedem uma vida digna e muitas vezes colocam em risco a própria sobrevivência de determinado grupo social.

Os números são assustadores. Atualmente o número de deslocados por desastres naturais supera os deslocados por violência, em 2015 foram 8,6 milhões de deslocados por violência e 19,2 milhões de pessoas deslocadas por desastres naturais. ${ }^{1}$

Um dos grandes impasses para o tratamento da realidade dos refugiados ambientais é a ausência de um reconhecimento normativo claro nos documentos internacionais. Em que pese existirem opiniões diversas, entendemos que, se no âmbito global, a categoria dos refugiados ambientais não encontra guarida, o mesmo não acontece no âmbito do Sistema Interamericano.

Os sistemas regionais de proteção reforçam os direitos humanos previstos nos tratados e declarações internacionais e apresentam-se como uma resposta para as dificuldades de implementação das regras de defesa dos direitos humanos no âmbito global.

Para possibilitar a análise do tratamento dos refugiados ambientais no âmbito do Sistema Interamericano, o presente artigo se divide em três partes. o primeiro momento dedica-se a explicitar os documentos internacionais que reconheceram o direito ao meio ambiente equilibrado como um direito humano e a inevitável vinculação entre a temática dos direitos humanos e do direito ambiental. Em um segundo momento, tratar-se-á da situação dos deslocados ambientais de maneira genérica, abordando rapidamente a situação dos deslocados ambientais internos, isto é, aqueles que não cruzam a fronteira de seu país. A terceira e última parte dirige-se exclusivamente àqueles que abandonam seu país de origem ou de residência habitual em razão de graves desequilíbrios ambientais e ao reconhecimento de sua situação feita na Declaração de Cartagena.

Dados do Internal Displacement Monitoring Centre, no relatório Global Estimates 2015: People displaced by disasters, 2015. Disponível em: <http://www.internal-displacement.org/assets/library/ Media/201507-globalEstimates-2015/20150713-global-estimates-2015-en-v1.pdf>. Acesso em: 12 set. 2016. 


\section{Meio ambiente equilibrado como direito humano}

Após as claras violações aos direitos humanos ocorridas na Segunda Guerra, a comunidade internacional se volta à reconstrução desses direitos, agora "como paradigma e referencial teórico a orientar a ordem internacional". ${ }^{2}$ O surgimento de Estados totalitários espalhou terror e provocou a destruição de povos inteiros, assim como suscitou a consciência de que sem o respeito aos direitos humanos a convivência pacífica das nações tornava-se impossível. ${ }^{3}$

0 enfrentamento das ofensas aos direitos humanos passa a ser uma obrigação primária dos Estados. Desse esforço conjunto cria-se um sistema global de proteção aos direitos humanos e diversos sistemas regionais. A criação das Nações Unidas, com a adoção da Declaração Universal dos Direitos Humanos em 1948, marca o início da internacionalização dos direitos humanos, nas palavras de Piovesan. ${ }^{4}$

A Declaração de 1948 tem como objetivo essencial estabelecer uma ordem internacional voltada à proteção e reconhecimento da dignidade humana, estabelecendo um patamar mínimo de preservação de direitos e valores que são compartilhados por todos. A concepção contemporânea dos direitos humanos é marcada pela universalidade e indivisibilidade. ${ }^{5}$ São direitos universais na medida em que a condição de pessoa é requisito único para o reconhecimento da titularidade desses direitos. ${ }^{6}$ Trata-se da "absoluta ruptura, com o legado nazista, que condicionava a titularidade de direitos à pertinência à determinada raça (a raça pura ariana)". ${ }^{7}$ São indivisiveis, pois a violação de um direito humano importa a violação dos outros, numa clara concepção de inter-relação e interdependência das diversas categorias de direitos humanos.

A própria Declaração Universal de 1948 contempla em seu bojo direitos civis e políticos, bem como direitos sociais, econômicos e culturais, já o direito ao meio ambiente sadio e seu reconhecimento como direito humano internacional demandou outros esforços e outras construções normativas.

Apesar da proteção ambiental ter sido inserida na agenda global em um momento posterior à inserção dos direitos humanos, essas duas áreas estão

PIOVESAN, Flávia. Direito ao desenvolvimento - Desafios contemporâneos, 2010, p. 96.

COMPARATO, Fábio Konder. A afirmação histórica dos direitos humanos, 2013.

PIOVESAN, Flávia. Direitos humanos e o direito constitucional internacional, 2013.

PIOVESAN, Flávia. Direito ao desenvolvimento - Desafios contemporâneos, 2010.

Não se pretende aqui a polarização de discussões universalistas ou relativistas, mas do reconhecimento de uma concepção multicultural dos direitos humanos defendida por Boaventura de Sousa Santos. "Uma concepção que em vez de recorrer a falsos universalismos, se organiza como uma constelação de sentidos locais, mutuamente inteligiveis, e se constitui em rede de referências normativas capacitantes" (SANTOS, 1997).

7 PIOVESAN, Flávia. Direitos humanos e o direito constitucional internacional, 2013, p.214. 
interligadas, na medida em que ambas estão preocupadas com o desenvolvimento e a promoção do bem-estar humano. ${ }^{8}$

O reconhecimento da indissociabilidade da proteção dos direitos humanos e das questões ambientais passa a tomar espaço na agenda global a partir da década de 60. Não poderia ser diferente, isto porque, como assevera Cançado Trindade: ${ }^{9}$

O quadro dos direitos humanos está inelutavelmente presente na consideração do regime de proteção do meio-ambiente humano em todos os aspectos: confrontando-nos aqui em última análise com a questão crucial da sobrevivência do gênero humano, com a asserção face às ameaças ao meio-ambiente - do direito humano fundamental de viver.

Segundo Real Ferrer $^{10}$ a transição de um direito orientado à proteção individualizada dos recursos para o direito ambiental se produz quando o homem toma consciência de que as alterações produzidas no ecossistema global podem influenciar as expectativas de subsistência no planeta. O mesmo autor propõe que a compreensão da evolução do direito ambiental se vista pelo enfoque cronológico encontra sua primeira "onda" na Conferência das Nações Unidas sobre o Meio Ambiente de 1972.

A conferência, que ficou conhecida como Conferência de Estocolmo, em razão do local de sua realização, representa um importante marco na aproximação entre os direitos humanos e o direito ambiental na seara internacional. Tanto assim, que a Declaração de Estocolmo, resultado da conferência, inicia seu texto afirmando que o meio ambiente natural e artificial são essenciais para o exercício dos direitos humanos (ONU, 1972). Para Cançado Trindade, ${ }^{11}$ foi na Declaração sobre o Meio Ambiente de Estocolmo que o direito fundamental ao meio ambiente foi reconhecido.

Antes da Conferência de Estocolmo o meio ambiente era tratado dissociado do homem e, mesmo não se revestindo da qualidade de tratado internacional, a Declaração de Estocolmo modifica o foco sobre o pensamento ambiental no planeta e enquadra-se ao lado de várias outras declarações memoráveis da ONU,

8 PATHAK, Puneet. Human Rights approach to environmental protection. OIDA - International Journal of Sustainable Development, v. 7, n. 1, 2014. Disponivel em: <https://ssrn.com/abstract=2397197>. Acesso em: 5 out. 2016.

9 Direitos humanos e meio ambiente: paralelo dos sistemas de proteção internacional, 1993, p. 50.

10 REAL FERRER, Gabriel. La construcción del derecho ambiental, 2013.

11 Direitos humanos e meio ambiente: paralelo dos sistemas de proteção internacional, 1993, 
como a própria Declaração de 1948 e a Declaração do Rio de Janeiro sobre o Meio Ambiente e Desenvolvimento em 1992. ${ }^{12}$

Em 1972 também foi estabelecido o Programa das Nações Unidas para o Meio Ambiente (PNUMA), com sede em Nairóbi no Quênia. Hoje o PNUMA é a principal autoridade para a definição de uma agenda ambiental global, promovendo uma coerente implementação do desenvolvimento sustentável dentro do sistema das Nações Unidas.

Ainda na esteira dos importantes documentos internacionais, em 1987, coordenado pela médica norueguesa Gro Harlem Brundtland, a Comissão Mundial sobre o Meio Ambiente e Desenvolvimento publicou o inovador relatório Nosso futuro comum, inserindo na pauta pública as discussões a respeito do desenvolvimento sustentável. O Relatório Brundtland é incisivo na constatação da impossibilidade de serem abordados problemas ambientais sem uma perspectiva ampla que englobe os fatores subjacentes à pobreza e às desigualdades mundiais. ${ }^{13}$

Parte-se daí todo um esforço teórico para o desenvolvimento do termo socioambientalismo, que reconhece que um novo paradigma de desenvolvimento deve promover a sustentabilidade estritamente ambiental, mas, também, a sustentabilidade social, contribuindo para a redução da pobreza e maior equidade. ${ }^{14}$ Trata-se do próprio reconhecimento do direito ambiental como direito humano e da sua natureza indivisível, na medida em que a violação de um direito humano importa a violação dos demais. ${ }^{15}$

Vários outros documentos jurídicos internacionais também realizaram a necessária aproximação entre as questões ambientais e as questões envolvendo os direitos humanos. Segundo Cançado Trindade, ${ }^{16}$ a II Reunião do Grupo de Consultores Jurídicos do PNUMA, que aconteceu em Genebra em 1991, também assinalou a importância do reconhecimento do direito a um meio ambiente sadio e do direito ao desenvolvimento como um direito humano.

No mesmo ano, o Relatório Final do Seminário Internacional sobre Países em Desenvolvimento e Direito Ambiental em Pequim ${ }^{17}$ afirmou haver um consenso

12 MAZZUOLI, Valério de Oliveira. A proteção internacional dos direitos humanos e o direito internacional do meio ambiente, 2013.

13 ONU, Organização das Nações Unidas. Princípios orientadores relativos aos deslocados internos, 1991.

14 SANTILI, Juliana. Socioambientalismo e novos direitos: proteção jurídica da diversidade biológica e cultural, 2015.

15 No mesmo sentido: "Respect for human rights, economic development, and environmental protection have been unified in the concept of sustainable development as a common concern of humanity. Other domains of international law, such as international trade, are instrumental in achieving the common interest but they are not themselves among the ultimate goals of international society. Instead, they are means to achieve the well-being of humanity as a whole. The terms of the UN Charter indicate that international peace and security, together with economic and social advancement of all peoples and individuals, are also necessary to ensure the overall advancement of humanity" (KISS; SHELTON, 2007, p. 14).

16 Direitos humanos e meio ambiente: paralelo dos sistemas de proteção internacional, 1993,

17 UNITED NATIONS. Final report of international law symposium on developing countries and international environmental law, 1991. 
geral da ligação entre a proteção ambiental e os direitos humanos, especialmente o direito à vida e o direito à saúde. 0 direito ao meio ambiente sadio e o direito ao desenvolvimento foram concebidos para reforçar e não para restringir outros direitos, em razão da sua indivisibilidade e interdependência. A proteção ambiental acendeu a uma questão de sobrevivência e de proteção à saúde humana.

No âmbito dos sistemas regionais de proteção dos direitos humanos, a Carta Africana dos Direitos Humanos e dos Povos, de 1981, estabelece em seu art. 24웅 "Todos os povos têm direito a um meio ambiente geral satisfatório, propício ao seu desenvolvimento", fazendo a introdução da temática da proteção ambiental em um documento de direitos humanos.

No âmbito dos sistemas regionais de proteção dos direitos humanos, a Carta Africana dos Direitos Humanos e dos Povos de 1981 estabelece em seu art. 24: "Todos os povos têm direito a um meio ambiente geral satisfatório, propício ao seu desenvolvimento", fazendo a introdução da temática da proteção ambiental em um documento de direitos humanos.

No âmbito do sistema regional interamericano, que tem aqui particular interesse por incidir sobre nosso país, o principal documento, qual seja, a Convenção Americana sobre Direitos Humanos de 1969, não inclui o direito ao meio ambiente sadio, mas o faz de forma expressa no Protocolo de San Salvador de 1988.

O protocolo apresenta a seguinte redação em seu art. 11, que trata do direito a um meio ambiente sadio: “1. Toda pessoa tem direito a viver em meio ambiente sadio e a contar com os serviços públicos básicos. 2. Os Estados Partes promoverão a proteção, preservação e melhoramento do meio ambiente". Ao se referir ao Protocolo de San Salvador, Cançado Trindade ${ }^{18}$ afirma que se trata do reconhecimento expresso, em um instrumento de direitos humanos, do direito humano a um meio ambiente equilibrado.

Tais documentos demonstram a possibilidade de compressão do direito ao meio ambiente equilibrado e sadio como um direito humano. Na medida em que tanto o sistema global como os sistemas regionais de proteção aos direitos humanos possuem como última ratio a proteção da vida; o meio ambiente sadio e o direito a paz são uma extensão ou corolários do direito à vida, pois não há que se falar em direitos humanos sem sua interface com a proteção ambiental.

Nesse mesmo sentido, Mazzuoli19 afirma que todo processo normativo internacional tem consequências no campo ambiental e nos direitos humanos e que, apesar de não ter sido expressamente colocado na Declaração de 1948 , o direito a um meio ambiente equilibrado é essencial para que os direitos e liberdades estabelecidos na declaração possam ser realizados plenamente.

18 Direitos humanos e meio ambiente: paralelo dos sistemas de proteção internacional, 1993.

19 A proteção internacional dos direitos humanos e o direito internacional do meio ambiente, 2013. 
Pela própria característica da historicidade dos direitos humanos, é natural que a luta pela incorporação e compreensão do direito ao meio ambiente sadio enquanto direito fundamental fosse progressiva e gradual. "Enquanto reivindicações morais, os direitos humanos nascem quando devem e podem nascer". ${ }^{20}$

Importante ressaltar, ainda, que o Brasil é parte dos principais tratados internacionais sobre o meio ambiente concluídos sob a tutela das Nações Unidas. O Brasil também foi um dos primeiros países a ratificar o Acordo de Paris em setembro de 2016, e teve destaque na seara ambiental ao sediar a Rio-92, e Rio + 20, importantes marcos para a construção de uma agenda global sustentável.

A atuação brasileira não poderia ser diferente, já que a asserção do direito à vida de todo ser humano, nos instrumentos internacionais, fez-se acompanhar da asserção de uma obrigação negativa (ninguém privar arbitrariamente a vida de outrem) e de uma obrigação positiva (adotar as providências necessárias para proteger e preservar a vida humana) para os Estados. ${ }^{21}$ As obrigações positivas criam uma necessidade de atuação dos Estados no sentido de garantia e efetividade dessas novas demandas.

E todas estas alterações no âmbito normativo começam a se fazer sentir nas cortes internacionais. Perceba-se que os instrumentos internacionais passam a associar a violação ao meio ambiente com a violação aos direitos humanos. A possibilidade de que as cortes que julgam violações de direitos humanos estabeleçam que a partir de violações ambientais é possível concluir pela violação de direitos humanos é um movimento denominado de greening dos direitos humanos. Já há casos admitidos perante a Corte Interamericana e a Corte Europeia que estão fundados em violações ambientais, mas em que ocorreu o reconhecimento de violação a direitos humanos. ${ }^{22}$

A compreensão do meio ambiente equilibrado como um direito humano, em razão de a própria existência da vida estar condicionada a um meio ambiente sadio, é essencial para a compreensão da categoria dos refugiados ambientais e suas consequências. Afinal, ligar direitos humanos e danos ambientais permite que os indivíduos utilizem os sistemas global e regional de proteção dos direitos humanos quando os Estados permitem uma degradação ambiental substancial. Afinal, a mais importante consequência é providenciar à vítima de degradação ambiental a possibilidade de acesso à justiça. ${ }^{23}$

PIOVESAN, Flávia. Direito ao desenvolvimento - Desafios contemporâneos, 2010, p. 6.

Direitos humanos e meio ambiente: paralelo dos sistemas de proteção internacional, 1993

PAMPLONA, Danielle Anne; ANNONI, Danielle. La protección del médio ambiente según el sistema interamericano de derechos humanos: socioambientalismo y el caso Belo Monte. In: Revista Catalana de Dret Ambiental, v. 7, n. 1, 2016, p.16.

23 PATHAK, Puneet. Human Rights approach to environmental protection. OIDA - International Journal of Sustainable Development, v. 7, n. 1, 2014. Disponivel em: <https://ssrn.com/abstract=2397197>. Acesso em: 5 out. 2016. 


\section{Deslocados ambientais}

A análise que se faz a seguir parte de uma abordagem integrada e coordenada das três vertentes do direito internacional de proteção da pessoa humana (direitos humanos, direito humanitário e direito dos refugiados) na já consagrada teoria das vertentes de Cançado Trindade. ${ }^{24}$ Isso porque a proteção integral da pessoa humana é o fim comum dessas três vertentes do direito internacional.

Nesse sentido Cançado Trindade ${ }^{25}$ afirma haver um íntimo vínculo entre os fluxos de refugiados e a proteção dos direitos humanos, porquanto as violações graves e amplas de direitos humanos acarretam fluxos intensos de refugiados. A proteção de refugiados e pessoas deslocadas há assim de ser apropriadamente coordenada com os mecanismos de proteção dos direitos humanos (global e regional).

Embora o fenômeno de pessoas que precisam deixar seus países de maneira definitiva ou temporária em razão de problemas de degradação ambiental não seja nenhuma novidade na história da humanidade, a expressão "refugiados ambientais" ganha destaque apenas na década de 80 , com a publicação do trabalho de El-Hinnawi intitulado Environmental refugees. ${ }^{26}$ A preocupação com o tema aparece reforçada com a publicação do primeiro Relatório do Painel Intergovernamental sobre Mudanças Climáticas - IPPCC ${ }^{27}$ de 1990, que alertava que o mais grave efeito da mudança climática é o deslocamento de milhões de pessoas. ${ }^{28}$

A própria terminologia não apresenta uniformidade de tratamento. São usados termos como: refugiados ecológicos, ecorrefugiados, migrantes ambientais, deslocados por razões ambientais e refugiados climáticos. Os diversos atores internacionais usam diferentes terminologias baseados em teorizações acadêmicas, ativismos ou ações políticas e dependendo das formas de proteção que pretendem ver emergente. ${ }^{29}$

Para fins de categorização e compreensão do texto, entende-se mais apropriada uma divisão entre duas realidades distintas. Adota-se, aqui, o termo "refugiados ambientais" apenas para aqueles que cruzam a fronteira de seu país, compreendendo essa categoria dentro do conceito amplo de refugiados. Os deslocados ambientais internos, por seu turno, permanecem em seu país de origem e merecem uma análise separada. Ambos encontram guarida nos sistemas

Tratado de Direito Internacional dos Direitos Humanos, 1997.

Direitos humanos e meio ambiente: paralelo dos sistemas de proteção internacional, 1993.

SERRAGLIO, Diogo Andreola. A proteção dos refugiados ambientais pelo direito internacional: uma leitura a partir da teoria da sociedade de risco, 2014.

Do inglês "Intergovernmental Panel on Climate Change".

PIGUET, Etienne. Climate change and forced migration, 2008.

COURNIL, Christel. The question of the protection of 'environmental refugees' from the Standpoint of International Law, 2009. 
de proteção de direito humanos, mas mantêm especificidades que não podem ser deixadas de lado.

Quando o texto se refere a todos aqueles que precisam deixar sua residência e seu local de origem pelas alterações no meio ambiente, usamos o termo "deslocados ambientais", fazendo referência tanto aos refugiados ambientais como aos deslocados internos.

Assim, deslocados ambientais são:

pessoas ou grupo de pessoas que, em razão de mudanças súbitas ou progressivas no ambiente, que afetam negativamente suas vidas ou condições de vida, são obrigados a deixar suas residências habituais, ou optam por fazê-lo, temporária ou permanentemente, e que se movem tanto em seu país ou no estrangeiro. ${ }^{30}$

Relatório lançado em 2016 pelo Observatório de Deslocamento Interno (IDMC - Internal Displacement Monitoring Centre) afirma que em 2015 foram 19,2 milhões de novos deslocados em razão de desastres. O gráfico a seguir apresenta os países que mais contemplam deslocados por violência e em seguida por desastres. Entre os países da América Latina, o Chile aparece em sexto lugar na lista dos países que mais possuem deslocados por desastres ambientais.

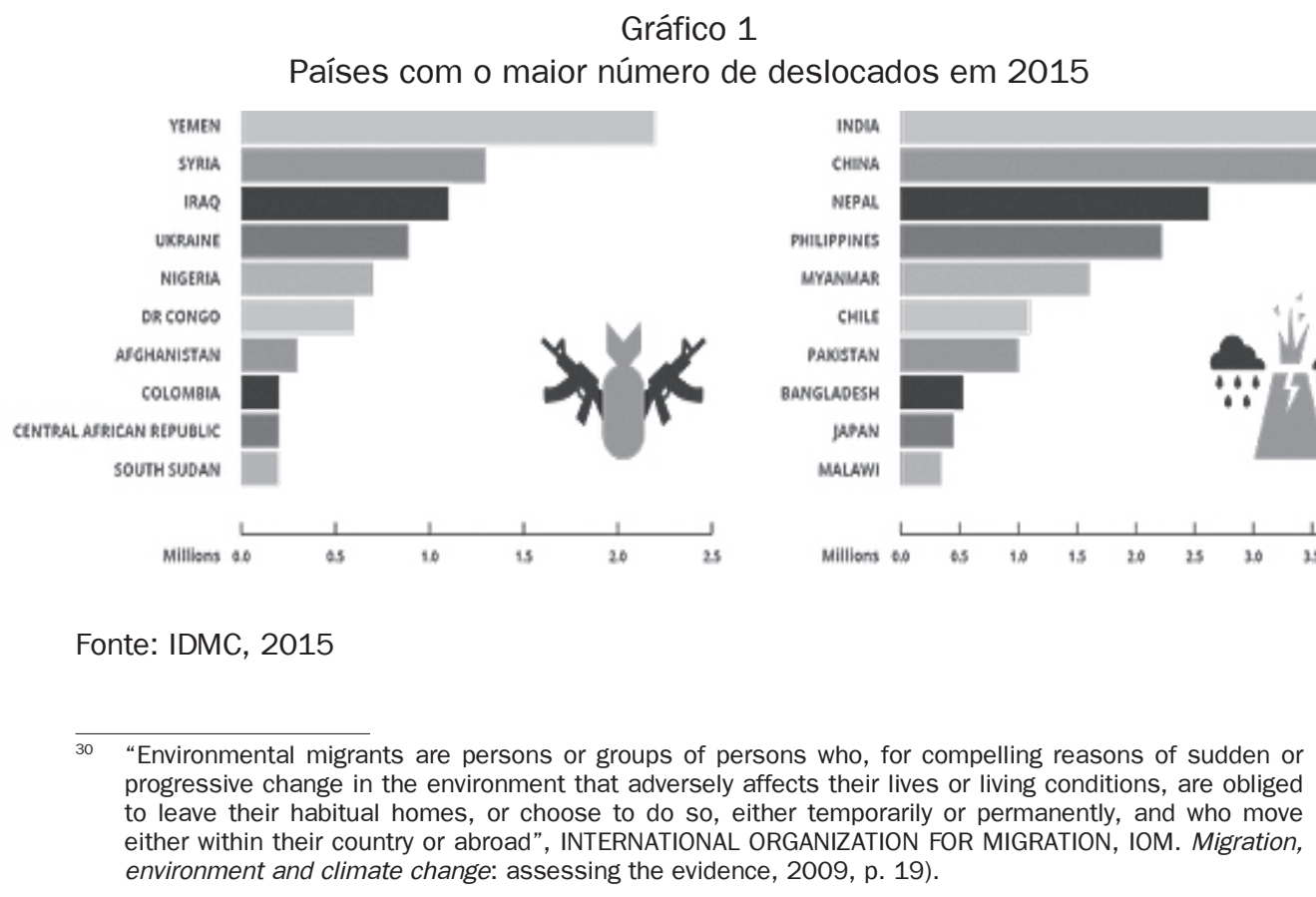


Relatório também do IDMC, ${ }^{31}$ específico para deslocados por desastres, afirma que desde 2008 uma média de 26,4 milhões de pessoas foram deslocadas de suas casas por desastres naturais, o que significa 1 (uma) pessoa deslocada a cada segundo no mundo.

Há, por certo, uma dificuldade em se estabelecer a causa exata dos deslocamentos, pois normalmente estamos diante de motivações complexas, que podem abranger ao mesmo tempo crises ambientais e crises sociais que, no geral, se confundem. O Relatório de Mudanças Ambientais e Climáticas do Alto Comissariado das Nações Unidas para Refugiados de 2015 aponta o exemplo de deslocados somalis para o Quênia, entre 2012 e 2013, motivados tanto pela seca e fome, como pelo terror espalhado por grupos armados como o Al Shabab.

McAdam $^{32}$ ressalta também que parte dos problemas para estatísticas mais apuradas é o número grande de variáveis, tais como saber exatamente quando a mudança climática será sentida e o nível de investimento e planejamento que existe para conter esses efeitos. Destaca por fim que a maior dificuldade é a capacidade de resiliência das pessoas, na medida em que alguns fogem imediatamente, alguns se deslocam mais tarde e outros nunca sairão de suas casas, sendo muito difícil prever quando as pessoas irão se deslocar de seus lugares de origem.

A dificuldade de estatísticas precisas não importa na impossibilidade de reconhecimento do fenômeno, muito menos abala a necessidade de a comunidade internacional lidar com a realidade de milhões de pessoas que se deslocaram ao longo dos últimos anos em razão de desastres ambientais. Tanto isso é verdade que, em 2011, a Conferência Nansen sobre Mudanças Climáticas e Deslocamentos no Século 21, convocada pelo Governo da Noruega entre os dias 5 e 7.7.2011, em Oslo, reforçou a necessidade de uma abordagem internacional mais coerente e consistente para a proteção das pessoas deslocadas. As respostas e políticas devem ser baseadas na não discriminação, consentimento, empoderamento, participação e parcerias com aqueles que são afetados pelas mudanças climáticas. ${ }^{33}$

No que diz respeito aos deslocados internos, a própria ONU reconhece sua existência ao consagrar em 1998 os Princípios Orientadores Relativos aos Deslocados Internos. Em suas metas e objetivos o documento afirma que são deslocados internos pessoas ou grupos de pessoas, forçados ou obrigados a fugir ou abandonar suas casas, particularmente, em consequência de conflitos

\footnotetext{
31 INTERNAL DISPLACEMENT MONITORING CENTRE, IDMC. Global Estimates 2015: People displaced by disasters, 2015.

32 MCADAM, Jane. Environmental Migration Governance, 2009.

33 UNHCR, The UN Refugees Agency. The Nansen Conference, 2011.
} 
armados, situações de violências generalizadas, violações dos direitos humanos ou calamidades humanas ou naturais, que não tenham atravessado uma fronteira internacionalmente reconhecida de um Estado. Perceba-se que aqui, expressamente, as questões ambientais são reconhecidas como causas de deslocamento.

O mesmo documento prevê como direitos dos deslocados internos o de sair do país, o de procurar asilo em outro país e o de ser protegido contra o regresso forçado e a reinstalação em qualquer lugar onde a sua vida, segurança, liberdade ou saúde possam ser colocadas em risco (Princípio 15).

Para o ACNUR, em 2014, a estimativa era de 26 milhões de deslocados internos ajudados pela agência em todo mundo, sendo os três países com o maior número de deslocados internos a Síria, a Colômbia e a República Democrática do Congo. ${ }^{34}$ O Princípio 25 dos Princípios Orientadores Relativos aos Deslocados Internos expressa que as autoridades nacionais têm o dever e a responsabilidade primários de prestar assistência aos deslocados internos, mas as organizações humanitárias têm o direito de oferecer seus serviços, sem que isso represente uma interferência nos assuntos internos.

Esse reconhecimento da ONU aos deslocados internos por causas naturais e a garantia a essas pessoas de aplicação de princípios clássicos dos refugiados, como o non-refoulement, só reforça o reconhecimento de que a proteção deve ser a mais ampla possível, independentemente da nomenclatura utilizada. Afinal, se há o reconhecimento de que as causas ambientais provocam as mesmas consequências de conflitos armados e perseguições políticas ou religiosas, não há que se remediar as consequências de modos diferentes.

\section{Refugiados ambientais}

A grande dificuldade, apontada por diversos especialistas no tema, é a falta de normatização ou de previsão nos documentos internacionais da categoria dos refugiados ambientais. Diversos autores afirmam a incapacidade da atual legislação internacional de fornecer proteção a essas pessoas.

Todavia, defende-se aqui que no âmbito do Sistema Interamericano de Proteção aos Direitos Humanos, os documentos existentes, seja no âmbito internacional, seja no doméstico brasileiro, são capazes de oferecer proteção à categoria dos deslocados ambientais. Há autores que temem que o uso da proteção dada aos refugiados para categorias como os deslocados ambientais enfraqueça o instituto do refúgio. ${ }^{35}$ Todavia, o que se advoga aqui é que, sem

\footnotetext{
34 UNHCR, The UN Refugees Agency. Deslocados internos, 2015.

35 JUBILLUT, Liliana Lyra; APOLINÁRIO, Silvia Menecucci O. S. A necessidade de proteção internacional no âmbito da migração, 2010.
} 
pleitear um alargamento do conceito, deve-se atentar para o fato de que graves alterações no meio ambiente podem representar graves violações aos direitos humanos. Não se trata de inserir toda e qualquer realidade dentro dos parâmetros do refúgio, mas reconhecer que o deslocamento forçado de pessoas se dá por diversas causas, inclusive a ambiental.

Para que se possa explorar o alcance e compreensão dos refugiados ambientais é necessária, inicialmente, uma incursão pelo reconhecimento e conceito dos refugiados lato sensu.

A criação da categoria jurídica do refúgio aparece somente no séc. XX, pós-II Guerra Mundial, e encontra sua fundamentação na solidariedade e cooperação internacional, mas diferente do instituto do asilo, não se trata de ato discricionário do Estado concessor, pois seu reconhecimento está vinculado a diplomas legais bem específicos. ${ }^{36}$

Em 1950, no âmbito da ONU, foi criado o Alto Comissariado das Nações Unidas para Refugiados (ACNUR) com o intuito de proteger e prestar assistências às vítimas de perseguição e violações generalizadas dos direitos humanos. No âmbito internacional o documento que conceitua e normatiza o instituto do refúgio é a Convenção das Nações Unidas sobre o Estatuto dos Refugiados de julho de 1951, com entrada em vigor em 22.4.1954.

$\mathrm{O}$ art. 1ำ do Estatuto dos Refugiados de 1951 define que é refugiado todo aquele que, em razão dos acontecimentos ocorridos antes de 1‥1.1951 e temendo ser perseguido por motivo de raça, religião, nacionalidade, grupo social ou opiniões políticas, se encontra fora de seu país de nacionalidade e não pode ou não quer valer-se da proteção desse país. O estatuto previa assim uma limitação temporal, pois somente poderia ser considerado refugiado aquele que tivesse seu fundamento calcado em fatos ocorridos antes de 1으 de janeiro daquele ano; além de uma limitação geográfica, já que os Estados poderiam prever a restrição apenas de fatos, os quais fundamentariam os pedidos de refúgio, ocorridos na Europa. Essa restrição deixou aos poucos o estatuto sem operacionalidade. ${ }^{37}$

A emergência de novas situações de conflitos e perseguições culminou na assinatura do Protocolo de 1967, no âmbito da Assembleia Geral da ONU, que entrou em vigor em 4 de outubro e retirou os limites de data e espaço para a definição de refugiados. O protocolo, porém, continuou mantendo a limitação para a caracterização do refúgio à violação de direitos civis e políticos. ${ }^{38}$

36 A diferença entre os institutos do asilo e refúgio apresenta-se bastante delimitada e explorada na obra de Liliana Jubillut denominada "O direito internacional dos refugiados e sua aplicação no orçamento jurídico brasileiro", 2007.

37 PAMPLONA, Danielle Anne; PIOVESAN, Flávia. O instituto do refúgio no Brasil: práticas recentes, 2015.

38 "Tal fato se deveu ao medo dos Estados desenvolvidos de uma ampliação do número de refugiados, o que não atendia aos seus interesses na época, e poderia, de fato, ocorrer uma vez que a Assembleia Geral da ONU era, nesse momento, dominada por Estados em desenvolvimento ou de menor desenvolvimento 
Em nível regional, o conceito de refugiado encontra-se mais ampliado. A Convenção Relativa aos Aspectos Específicos dos Refugiados Africanos (1969), além do conceito já previsto na Convenção de 1951, define como refugiado qualquer pessoa que, devido a uma agressão, ocupação externa, dominação estrangeira ou acontecimento que perturbe gravemente a ordem pública numa parte ou na totalidade do seu país de origem ou do país de que tem nacionalidade, seja obrigada a deixar o lugar da residência habitual para procurar refúgio noutro lugar fora do seu país de origem ou de nacionalidade. A violência sofrida pelo indivíduo pode vir de outro Estado ou se manifestar em apenas uma região do Estado. Consideram Jubillut e Apolinário: ${ }^{39}$

Esse instrumento inclui entre os refugiados qualquer pessoa que, em razão de uma agressão, ocupação externa, dominação estrangeira, ou de acontecimento que perturbe gravemente a ordem pública, em uma parte ou na totalidade do seu país de origem ou do país de que tem nacionalidade, seja obrigada a deixar seu país. Deste modo, não se exige dessas pessoas o receio fundado de perseguição.

Por outro lado, na região das Américas, a Declaração de Cartagena também amplia de maneira importante o conceito de refugiado e, no presente texto, merece especial atenção, tendo em vista que sua adoção é recomendada pela Organização dos Estados Americanos (OEA) e um número relevante de Estados já a incorporaram na íntegra ou com algumas modificações. ${ }^{40}$

A Declaração de Cartagena foi adotada em novembro de 1984 em Cartagena, Colômbia, em um Colóquio sobre Proteção Internacional dos Refugiados na América Central, México e Panamá denominado Problemas Jurídicos e Humanitários, e passa a recomendar a adoção do conceito que considere também como refugiados as pessoas que tenham fugido dos seus países porque a sua vida, segurança ou liberdade tenham sido ameaçadas pela violência generalizada, a agressão estrangeira, os conflitos internos, a violação maciça dos direitos humanos ou outras circunstâncias que tenham perturbado gravemente a ordem pública. Perceba-se, portanto, que se trata de um conceito mais amplo da categoria de refugiado, incluindo como razão para a fuga a ameaça representada por violações maciças de direitos humanos.

relativo. Desse modo, optou-se pela aprovação de um documento curto que se limitava a revogar as reservas e que não propiciava a discussão material do tema" (JUBILLUT, 2007, p. 88).

39 JUBILLUT, Liliana Lyra; APOLINÁRIO, Silvia Menecucci O. S. A necessidade de proteção internacional no âmbito da migração, 2007, p. 283.

40 JUBILLUT, Liliana Lyra; MADUREIRA, André de Lima. Os desafios de proteção aos refugiados e migrantes forçados no marco de Cartagena + 30, 2014. 
Após 10 anos da Declaração de Cartagena ocorreu o primeiro encontro revisional que resultou na adoção da Declaração sobre Refugiados e Pessoas Deslocadas de 1994. Nesse momento já se reconhece a necessidade de proteção aos deslocados internos. Após 20 anos adotou-se a Declaração e o Plano de Ação do México (PAM) para fortalecer a proteção dos refugiados na América Latina. Em 2004 a reunião, que ficou conhecido como Cartagena +30, adotou a Declaração e Plano de Ação de Brasília, em que os países concordaram em trabalhar juntos para manter os mais elevados padrões de proteção nos níveis internacional e regional, para implementar soluções inovadoras para os refugiados e pessoas deslocadas, e para acabar com a difícil situação enfrentada pelas pessoas apátridas na região. Todos os documentos são resultado do esforço da Declaração de Cartagena em ampliar o conceito de refugiado no âmbito do sistema interamericano. Assim, os países que aprovaram a declaração reconhecem que há novos desafios no tratamento de refugiados e deslocados e se comprometeram em, até o ano de 2014, identificar e enfrentar as causas dos deslocamentos.

A partir daí, portanto, “[O] alargamento da condição de refugiado é evidente. A partir de então, a violação maciça de direitos é fundamento para a concessão do refúgio". ${ }^{41}$ Ainda que não seja para se alcançar a equivalência nominal das duas situações, e se mantenha a denominação de refugiados e de deslocados, há que se almejar que a proteção seja igual para ambos. Essa ampliação nos documentos internacionais sobre refugiados do direito internacional dos diretos humanos permite passar de um foco na situação de perseguição individual, para a situação objetiva do país de origem, analisando a proteção dos direitos humanos de forma mais ampliada. ${ }^{42}$

A compreensão de graves violações de direitos humanos não é objetiva. Verifica-se grave violação de direitos humanos em casos de guerras civis, regimes ditatoriais ou em casos em que os países são incapazes de garantir a liberdade, a segurança ou a vida das pessoas, além do mais, a situação objetiva do país é por si só elemento caracterizador da condição de refugiado. ${ }^{43}$

Segundo Cançado Trindade ${ }^{44}$ a caracterização de "graves violações de direitos humanos" usa como critério as ocorrências em que um número grande de pessoas é lesado. Isso porque a declaração surge inicialmente justamente movida pela massa de refugiados na América Central, México e Panamá.

Tendo em mente especificamente os deslocados ambientais, parece razoável a defesa da ideia de que essa categoria está compreendida na proteção oferecida

\footnotetext{
41 PAMPLONA, Danielle Anne; PIOVESAN, Flávia. O instituto do refúgio no Brasil: práticas recentes, 2015, p. 46.

42 JUBILLUT, Liliana Lyra. O direito internacional dos refugiados e sua aplicação no orçamento jurídico brasileiro, 2010.

43 JUBILLUT, Liliana Lyra; MADUREIRA, André de Lima. Os desafios de proteção aos refugiados e migrantes forçados no marco de Cartagena + 30, 2014.

44 Direitos humanos e meio ambiente: paralelo dos sistemas de proteção internacional, 1993.
} 
pela Declaração de Cartagena, no momento em que a declaração amplia a possibilidade de categorização de refugiado a todos que sofrerem graves violações dos direitos humanos. Todo o desenvolvimento teórico apresentando na primeira parte do artigo leva à compreensão do direito ao meio ambiente equilibrado, como direito humano e, por consequência, à inexistência dessa condição como uma grave violação de direitos humanos. Grave, pois estamos falando da própria condição de sobrevivência que fica impedida em alguns casos de deslocados ambientais. ${ }^{45}$

Já Cançado Trindade ${ }^{46}$ aponta nesse sentido. Porém, o autor propõe uma distinção entre desastres naturais e desastres ambientais. Para ele as vítimas de desastres naturais puros, como vulcões e terremotos, permaneceriam fora do âmbito da Declaração de Cartagena, mas as vítimas de desastres ambientais poderiam recair sob "as outras circunstâncias".

Parece, porém, que "graves violações dos direitos humanos" suporta a categoria dos deslocados ambientais, sejam quais forem suas causas. Pela própria característica de universalidade, indivisibilidade e historicidade, podemos compreender que não só o direito ao meio ambiente equilibrado é um direito humano como sua ausência importa violações de outros direitos humanos.

Além do mais, a própria distinção entre desastres naturais e desastres ambientais, que seriam decorrentes da ação humana, apresenta uma dificuldade quando aceitamos que a ação humana vem, sistematicamente, alterando e impactando negativamente o meio ambiente.

Nesse sentido, o desastre ecológico pode ter como causa estritamente a ação humana, decorrente do desenvolvimento de atividades e tecnologias ditas perigosas e que envolvem certo nível de risco; ou ser produto de fenômenos naturais, nos quais também incidem fatores humanos, a exemplo do agravamento de fenômenos climáticos decorrentes do aquecimento global, em grande medida provocado pela ação humana. ${ }^{47}$

45 Nesse sentido o Caso Tuvalu, nação composta por nove pequenas ilhas no sudoeste do Oceano Pacífico que sofre consequências severas da mudança climática. Uma de suas menores ilhas, inclusive, desapareceu completamente em 1997, como explica Diogo Serraglio, na obra A proteção dos refugiados ambientais pelo direito internacional: uma leitura a partir da teoria da sociedade de risco, 2014. Estaríamos diante de um caso de apátridas por razões ambientais. Para ver mais nesse sentido, vide PARK, Susin. Climate change and the risk of statelessness: the situation of low-lying Island States. Legal and Protection Policy Research, 2011.

46 Direitos humanos e meio ambiente: paralelo dos sistemas de proteção internacional, 1993.

47 VIEIRA, Ricardo Stanziola. A construção do direito ambiental e da sustentabilidade: reflexões a partir da conjuntura da Conferência das Nações Unidas sobre o Desenvolvimento sustentável (RIO +20). 2012, p. 373. 
A inserção da categoria dos deslocados ambientais na Declaração de Cartagena não é feita sem dificuldades, eis que há a necessidade de perseguição ou fundado temor para a caracterização do refúgio, o que impediria essa interpretação. Isso porque a terceira conclusão da declaração conta com a seguinte redação:

\begin{abstract}
Terceira - Reiterar que, face à experiência adquirida pela afluência em massa de refugiados na América Central, se toma necessário encarar a extensão do conceito de refugiado tendo em conta, no que é pertinente, e de acordo com as características da situação existente na região, o previsto na Convenção da OUA (artigo 1., parágrafo 2) e a doutrina utilizada nos relatórios da Comissão Interamericana dos Direitos Humanos. Deste modo, a definição ou o conceito de refugiado recomendável para sua utilização na região é o que, além de conter os elementos da Convenção de 1951 e do Protocolo de 1967, considere também como refugiados as pessoas que tenham fugido dos seus países porque a sua vida, segurança ou liberdade tenham sido ameaçadas pela violência generalizada, a agressão estrangeira, os conflitos internos, a violação maciça dos direitos humanos ou outras circunstâncias que tenham perturbado gravemente a ordem pública. ${ }^{48}$
\end{abstract}

No momento em que a declaração exige que para a configuração de refugiado sejam utilizados os mesmos elementos da Convenção de 1951 e do Protocolo de 1967, há necessidade da ocorrência de "perseguição". Porém, Jubillut e Apolinário, ${ }^{49}$ ao tratarem dos deslocados por desenvolvimento, afirmam que um futuro com fome e doenças é motivo que compele o indivíduo à migração, mesmo não havendo uma perseguição configurada. Parece evidente que graves situações de desequilíbrio ambiental caminham de modo absolutamente conexo com violações de direito à saúde, doenças e fome.

Nesses casos, há elementos para se argumentar a aplicação da proteção estendida nos termos da Convenção Africana de 1969 e da Declaração de Cartagena de 1984, que não demandam a existência da perseguição para a concessão da proteção do refúgio, mas somente a configuração de situações objetivas, entre as quais se destaca a vida ameaçada por violação maciça dos direitos humanos, ou ainda a relação com a ordem pública, em face de um Estado fraco e incapaz de prover o mínimo necessário para se viver. (JUBILLUT, APOLINÁRIO, 2009, p. 290)

48 OEA. Declaração de Cartagena. 1984.

49 JUBILLUT, Liliana Lyra; APOLINÁRIO, Silvia Menecucci O. S. A necessidade de proteção internacional no âmbito da migração, 2009. 
Embora neguem a classificação de refugiados aos refugiados ambientais, as autoras o fazem analisando exclusivamente os refugiados ambientais no sistema global e afirmam que a necessidade de perseguição ou fundado temor de perseguição impede que se reconheça a essas pessoas a condição de refugiados, com base da Convenção de 1951. Não fazem, porém, a análise dos refugiados ambientais examinando especificamente os sistemas regionais.

Parece claro que temos duas situações bastante distintas de tratamento. Se no âmbito global a necessidade de perseguição é fator essencial, nos sistemas regionais americano e africano isso não acontece. Assim, a caracterização dos refugiados ambientais como refugiados em sentido amplo é possível somente no âmbito dos sistemas americano e africano de proteção aos direitos humanos.

Para além disso, os sistemas regionais são o locus mais adequado para a proteção dos deslocados ambientais, na medida em que estão mais próximos da realidade regional e representam um ponto de partida para posteriores discussões globais. Afinal, "una respuesta de tipo regional, si bien puede parecer en principio poco ambiciosa, podría constituir el comienzo de posteriores esfuerzos internacionales más amplios" (FERNANDÉZ, 2015, p. 43).

Não se pretende, por certo, desconsiderar a importância dos esforços de inúmeros estudiosos, organizações e entidades internacionais na tentativa de uma normatização expressa em âmbito global para os refugiados ambientais. Até porque o gráfico a seguir mostra que a maior parte das pessoas do mundo deslocadas por desastres estão na Ásia e não na África ou nas Américas.

\section{Gráfico 2}

Regiões com o maior número de deslocados em razão de desastres em 2015

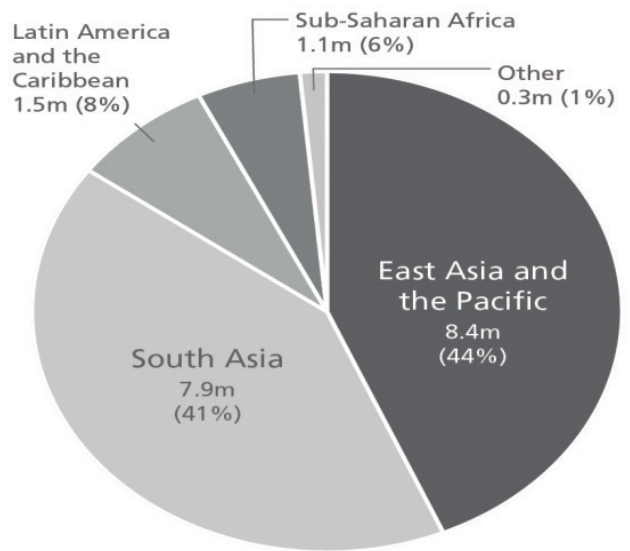

Fonte: IDMC, 2016. 
No mais, é preciso compreender que o fato de os deslocados ambientais estarem protegidos pelo Sistema Interamericano de Proteção dos Direitos Humanos não significa o fim das discussões, mas o início de novos debates que se apresentam necessários. O maior esforço precisa convergir para que seja encontrada efetividade nos mecanismos de proteção dos refugiados e deslocados espalhados no mundo, ou seja, por quaisquer causas.

De fato, o problema não se resume à categorização normativa ou não, mas se espraia para a escassez de recursos, inexistências de políticas públicas nesse sentido, intolerância e preconceito, que em geral são encontrados nos países que acabam por receber essas pessoas. Esse sim é o pano de fundo de toda discussão envolvendo refugiados e deslocados. Tudo isso agravado pelo fato de que em momentos de grandes ondas migratórias, como a que se presencia hoje, as regulamentações já existentes sofrem restrições de interpretação. ${ }^{50}$

Há que se fazer esforços. A implementação da solidariedade planetária necessita de uma mudança profunda em nosso comportamento e na forma de entender muitas instituições fortemente arraigadas em nossos padrões culturais. ${ }^{51}$ Mas colaboração e solidariedade são palavras de ordem para a sustentabilidade global. ${ }^{52}$

\section{Conclusões}

Apesar de a proteção ambiental só ter sido inserida na agenda global a partir da década de 60 , a ligação entre a sustentabilidade ambiental e os direitos humanos se faz evidente, na medida em que ambas as temáticas estão preocupadas com o desenvolvimento e promoção do bem-estar humano.

A partir da Conferência de Estocolmo vários documentos internacionais se preocuparam em fazer a devida aproximação entre o direito ambiental e os direitos humanos, com importante destaque, no âmbito regional, ao Protocolo de San Salvador, que reconhece expressamente o direito humano a um meio ambiente equilibrado. Tal reconhecimento permite que os indivíduos utilizem os sistemas

50 Como exemplo a decisão do Conare do Brasil, diante da entrada crescente de haitianos no país, que criou uma interpretação bastante restritiva da Lei no 9.474/97, que define os mecanismos para a implementação do Estatuto do Refugiado de 1951. Momento em que o Brasil perde a oportunidade de ser pioneiro em reconhecer como refugiados aqueles que se deslocam devido a graves e generalizadas violações aos direitos humanos (PAMPLONA; PIOVESAN, 2015). O caso dos haitianos, que inclusive tiveram seus problemas sociais já existentes profundamente agravados por um terremoto em 2010 e, recentemente, pela passagem do furacão Matthew, é exemplo das múltiplas causas motivadoras dos deslocamentos, incluindo a degradação ambiental.

51 REAL FERRER, Gabriel. Sostenibilidad, transnacionalidad y transformaciones del derecho, 2012.

52 CRUZ, Paulo Márcio; BODNAR, Zenildo. O novo paradigma do direito na era da pós-modernidade, 2012. 
global e regional de proteção dos direitos humanos quando os Estados permitem uma degradação ambiental substancial.

Deslocados ambientais são pessoas ou grupo de pessoas que, em razão de mudanças súbitas ou progressivas no ambiente, que afetam negativamente suas vidas ou condições de vida, são obrigados a deixar suas residências habituais, ou optam por fazê-lo, temporária ou permanentemente, e que se movem dentro de seu país ou para terras estrangeiras. Dentro dessa categoria encontramos os refugiados ambientais, que cruzam a fronteira de um Estado, e os deslocados internos, que permanecem em seu país de origem ou de residência habitual.

Os deslocados ambientais internos foram reconhecidos pela ONU nos Princípios Orientadores Relativos aos Deslocados Internos de 1998 e, no momento em que cruzam a fronteira de seu país, são protegidos por princípios típicos de refugiados, como o princípio do non-refoulement. No que diz respeito aos deslocados ambientais, sustenta-se o seu reconhecimento na Declaração de Cartagena, já que sofrem graves violações de direitos humanos quando a ausência de um meio ambiente equilibrado exige que abandonem suas casas e os força à migração. Diante desse reconhecimento entende-se que o Sistema Interamericano de Direitos Humanos é o locus adequado para a proteção daqueles que se encontram em situação análoga a de refúgio motivado por causas ambientais.

Tem-se claro, porém, que esse reconhecimento pretende apenas o fim das discussões a respeito da ausência normativa para os deslocados ambientais em nosso sistema regional, mas avanços globais se fazem urgentes nesse sentido.

Por fim, para que se efetive a proteção dos refugiados ambientais na Declaração de Cartagena, faz-se necessário um esforço conjunto dos países vinculados à OEA em busca de solidariedade ambiental e consequentemente humanitária.

\title{
The recognition of environmental refugees in the framework of the Inter-American System for the Protection of Human Rights
}

\begin{abstract}
This article discusses the recognition of the category of environmental refugees within the framework of the Inter-American System for the Protection of Human Rights. Environmental refugees are all those who need to cross the border of their country, abandoning their usual residences, due to degrading environmental conditions that prevent a dignified life and often endanger the very survival of a particular social group. The recognition of environmental refugees is supported in the Cartagena Declaration, as environmental refugees suffer serious violations of human rights when the absence of a balanced environment requires that they leave their homes and force them to migrate. In view of this recognition in the Cartagena Declaration, we understand that the Inter-American Human Rights System is the appropriate locus for the protection of those who are in a situation of refuge motivated by environmental causes.
\end{abstract}

Keywords: Environmental refugees. Inter-American System for the Protection of Human Rights. Declaration of Cartagena. 


\section{Referências}

COMISSÃO AFRICANA DOS DIREITOS HUMANOS E DOS POVOS. Carta Africana dos Direitos Humanos e dos Povos. 1981. Disponível em: <http://www.achpr.org/pt/instruments/ achpr/>. Acesso em: 15 out. 2016.

COMPARATO, Fábio Konder. A afirmação histórica dos direitos humanos. 10. ed. 2. tir. São Paulo: Saraiva, 2013.

COURNIL, Christel. The question of the protection of 'environmental refugees' from the Standpoint of International Law. Migration and Climate Change, nov. 2009. Disponivel em: <https://ssrn.com/abstract=1994357>. Acesso: 20 out. 2016.

CRUZ, Paulo Márcio; BODNAR, Zenildo. O novo paradigma do direito na era da pósmodernidade. In: PRIER, Michel; SILVA, José Antonio Tietzmman (Org.). Instrumentos jurídicos para a implementação do desenvolvimento sustentável. Goiânia: Editora PUC Goiás, 2012. v. 2.

FERNÁNDEZ, María José. Refugiados, cambio climático y derecho internacional. Revista Migraciones Forzadas - Desastres y desplazamiento en un clima cambiante, n. 49, jun. 2015.

INTERNAL DISPLACEMENT MONITORING CENTRE, IDMC. Global Estimates 2015: People displaced by disasters. 2015. Disponível em: <http://www.internal-displacement.org/assets/ library/Media/201507-globalEstimates-2015/20150713-global-estimates-2015-en-v1.pdf>. Acesso em: 12 set. 2016.

INTERNAL DISPLACEMENT MONITORING CENTRE, IDMC. Global Report on Internal Displacement. 2016. Disponível em: <http://www.internal-displacement.org/globalreport2016/>. Acesso em: 25 out. 2016.

INTERNATIONAL ORGANIZATION FOR MIGRATION, IOM. Migration, environment and climate change: assessing the evidence. 2009. Disponivel em: <http://publications.iom.int/system/ files/pdf/migration_and_environment.pdf>. Acesso em: 20 out. 2016.

JUBILLUT, Liliana Lyra. O direito internacional dos refugiados e sua aplicação no orçamento jurídico brasileiro. São Paulo: Método, 2007.

JUBILLUT, Liliana Lyra; APOLINÁRIO, Silvia Menecucci O. S. A necessidade de proteção internacional no âmbito da migração. Revista Direito GV, São Paulo, jan./jun. 2010. Disponível em: <http://www.scielo.br/pdf/rdgv/v6n1/13.pdf>. Acesso em: 3 out. 2016.

JUBILLUT, Liliana Lyra; MADUREIRA, André de Lima. Os desafios de proteção aos refugiados e migrantes forçados no marco de Cartagena + 30. REMHU, Rev. Interdiscip. Mobil. Hum., Brasília, v. 22, n. 43, p. 11-33, dez. 2014. Disponivel em: <http://www.scielo.br/scielo. php?script=sci_arttext\&pid=S1980-85852014000200002\&lng=en\&nrm=iso>. Acesso em: 2 out. 2016.

KISS, Alex; SHELTON, Dinah L. Guide to International Environmental Law. GWU Law School Public Law Research Paper, n. 347, 2007. Disponível em: <https://ssrn.com/ abstract=1012092>. Acesso em: 10 out. 2016.

MAZZUOLI, Valério de Oliveira. A proteção internacional dos direitos humanos e o direito internacional do meio ambiente. Argumenta Journal Law, Jacarezinho, n. 9, p. 159-186, fev. 
2013. Disponível em: <http://seer.uenp.edu.br/index.php/argumenta/article/view/117>. Acesso em: 16 out. 2016.

MCADAM, Jane. Environmental Migration Governance. UNSW Law Research Paper, n. 2009-1. Disponivel em: <https://ssrn.com/abstract=1412002>. Acesso em: 20 out. 2016.

OEA. Declaração de Cartagena. 1984. Disponivel em: <http://www.acnur.org/fileadmin/ scripts/doc.php?file=fileadmin/Documentos/portugues/BD_Legal/Instrumentos_ Internacionais/Declaracao_de_Cartagena>. Acesso em: 10 ago. 2016.

ONU, Organização das Nações Unidas. Convenção relativa ao Estatuto dos Refugiados de 1951. Disponível em: <http://www.acnur.org/Convencao_relativa_ao_Estatuto_dos_ Refugiados.pdf>. Acesso em: 22 set. 2016.

ONU, Organização das Nações Unidas. Declaração da Conferência das Nações Unidas sobre o Meio Ambiente. 1972.

ONU, Organização das Nações Unidas. Nosso futuro comum. 2. ed. Rio de Janeiro: Editora da Fundação Getúlio Vargas, 1991.

ONU, Organização das Nações Unidas. Princípios orientadores relativos aos deslocados internos. 1998. Disponivel em: <http://www.acnur.org/fileadmin/Documentos/portugues/ BD_Legal/Documentos_da_ONU/Principios_orientadores_relativos_aos_deslocados_ internos_1998.pdf?view=1>. Acesso em: 5 set. 2016.

OUA. Convenção Relativa aos Aspectos Específicos dos Refugiados Africanos. 1969. Disponível em: <www.acnur.org/t3/portugues/recursos/documentos/>. Acesso em: 2 set. 2016.

PAMPLONA, Danielle Anne; ANNONI, Danielle. La protección del médio ambiente según el sistema interamericano de derechos humanos: socioambientalismo y el caso Belo Monte. In Revista Catalana de Dret Ambiental, v. 7, n. 1, 2016, pp.1-27.

PAMPLONA, Danielle Anne; PIOVESAN, Flávia. O instituto do refúgio no Brasil: práticas recentes. Revista de Direitos Fundamentais e Democracia, v. 17, n. 17, jan./jun. 2015.

PARK, Susin. Climate change and the risk of statelessness: the situation of low-lying Island States. Legal and Protection Policy Research, 2011.

PATHAK, Puneet. Human Rights approach to environmental protection. OIDA - International Journal of Sustainable Development, v. 7, n. 1, 2014. Disponivel em: <https://ssrn.com/ abstract=2397197>. Acesso em: 5 out. 2016.

PIGUET, Etienne. Climate change and forced migration. New Issues in Refugee Research, n. 153, jan. 2008. Disponível em: <http://www.unhcr.org/research/RESEARCH/47a316182. pdf>. Acesso em: 10 out. 2016.

PIOVESAN, Flávia. Direito ao desenvolvimento - Desafios contemporâneos. In: PIOVESAN, Flávia; SOARES, Inês Virgínia Prado. Direito ao desenvolvimento. Belo Horizonte: Fórum, 2010.

PIOVESAN, Flávia. Direitos humanos e o direito constitucional internacional. 14. ed. rev. e atual. São Paulo: Saraiva, 2013.

REAL FERRER, Gabriel. La construcción del derecho ambiental. Novos Estudos Jurídicos, v. 18, n. 3, p. 347-368, dez. 2013. 
REAL FERRER, Gabriel. Sostenibilidad, transnacionalidad y transformaciones del derecho. In: PRIEUR, Michel; SILVA, José Antonio Tietzmman (Org.). Instrumentos jurídicos para a implementação do desenvolvimento sustentável. Goiânia: Editora PUC Goiás, 2012. v. 2.

SANTILI, Juliana. Socioambientalismo e novos direitos: proteção jurídica da diversidade biológica e cultural. São Paulo: Peirópolis, 2015.

SANTOS, Boaventura de Sousa. Por uma concepção multicultural de direitos humanos. Revista Crítica de Ciências Sociais, Coimbra, n. 48, jun. 1997.

SERRAGLIO, Diogo Andreola. A proteção dos refugiados ambientais pelo direito internacional: uma leitura a partir da teoria da sociedade de risco. Curitiba: Juruá, 2014.

TRINDADE, Ântonio Augusto Cançado. Direitos humanos e meio ambiente: paralelo dos sistemas de proteção internacional. Porto Alegre: Sergio Antonio Fabris Editor, 1993.

TRINDADE, Ântonio Augusto Cançado. Tratado de Direito Internacional dos Direitos Humanos. Porto Alegre: Sergio Antonio Fabris Editor, 1997. v. 1.

UNHCR, The UN Refugees Agency. The environment and climate change. 2015. Disponivel em: <http://www.unhcr.org/540854f49.pdf>. Acesso em: 3 set. 2016.

UNHCR, The UN Refugees Agency. The Nansen Conference. Climate Change and Displacement in the $21^{\text {st }}$ Century. Oslo, 2011. Disponivel em: <http://www.unhcr.org/4ea969729.html\#_ga $=1.113211719 .211475623 \cdot 1471960465>$. Acesso em: 22 out. 2016 .

UNHCR, The UN Refugees Agency. Deslocados internos. 2016. Disponivel em: <http://www. acnur.org/portugues/quem-ajudamos/deslocados-internos/>. Acesso em: 20 set. 2016.

UNITED NATIONS. Final report of international law symposium on developing countries and international environmental law. Beijing, 1991. Disponível em: <http://historico.juridicas. unam.mx/publica/librev/rev/iidh/cont/13/doc/doc30.pdf>. Acesso em: 15 out. 2016.

VIEIRA, Ricardo Stanziola. A construção do direito ambiental e da sustentabilidade: reflexões a partir da conjuntura da Conferência das Nações Unidas sobre o Desenvolvimento sustentável (RIO +20). In: PRIEUR, Michel; SILVA, José Antonio Tietzmman (Org.). Instrumentos jurídicos para a implementação do desenvolvimento sustentável. Goiânia: Editora PUC Goiás, 2012. v. 2.

Informação bibliográfica deste texto, conforme a NBR 6023:2002 da Associação Brasileira de Normas Técnicas (ABNT):

DANIELE, Anna Luisa Walter de Santana; PAMPLONA, Danielle Anne. O reconhecimento dos refugiados ambientais no âmbito do Sistema Interamericano de Proteção aos Direitos Humanos. Direitos Fundamentais \& Justiça, Belo Horizonte, ano 11, n. 37, p. 219-240, jul./dez. 2017.

Recebido em: 06.03.2017

Pareceres: 22.04.2017 e 21.06.2017

Aprovado em: 17.10.2017 